\title{
Nested Configurations of Interorganizational Information Systems: Observations in the German Furniture Industry
}

\author{
Norbert Frick \\ Deutsche Bundesbank University of Applied Sciences \\ norbert.frick@bundesbank.de
}

\begin{abstract}
Interorganizational information systems (IOIS) support inter-company processes in the German furniture industry for more than 25 years. Still, there are deficiencies in process integration and differences in IOIS infrastructures. New market participants struggle to adopt the right IOIS for their purposes. Current adoption models lack to understand and manage IOIS adoption on an industry level. Lyytinen and Damsgaard's configurational analysis for IOIS adoption considers enterprise networks as configurations of interorganizational integration that correspond to a stable pattern of cooperation forms. The configuration analysis is applied in the German furniture industry to identify and explain factors that influence an IOIS adoption decision and constitute stable IOIS configurations. Data collection in two industry segments shows four configuration types in 17 configurations characterized by 39 influencing factors. New market participants must consider the adoption of several IOIS at once in so-called nested configurations to gain access to all relevant exchange relations.
\end{abstract}

\section{Introduction}

The division of labor at national and international level is constantly increasing in the networked world. Concentration on specific parts of the value chain is leading to increased use of interorganizational systems. Underlying business models are changing, as are the organizational forms that support them [1]. Practice shows that potential cooperation partners struggle with identifying forms of interorganizational integration that suit them best ([2], [3], [4]). Still, consideration of the complexity of interorganizational cooperation and the associated interorganizational integration rarely succeeds ([5], [6]).

One industry that is affected by the increasing need to form interorganizational networks among its industry participants is the furniture industry in
Germany. The order-to-build business models are supported by multi-tier networks ensuring the sales process, the supply of raw materials for production and the installation of the final products. Despite the use of established interorganizational information systems (IOIS) for planning and delivery of highly configurable products, consistently high complaint rates of up to $40 \%$ are evident. Trends like digitalization of sales processes, entrance of new niche players or the current mergers and acquisition phase put additional pressure on the so-far inefficient supply chain and challenge existing and new market participants alike to rethink and change their way of interaction with their business partners and consequently their adoption/ use of IOIS.

We find studies in several industries that seek to gain a deeper understanding of the characteristics of interorganizational cooperation to guide practitioners in IOIS adoption (that is the process of starting to use a new IOIS) and gain insights of the complex interactions (see [6], [7], [8] for a brief selection). Most of these works provide model-based descriptions (including [8], [9]), that usually consider only subsections of reality (for example the technical implementation or the impact of an IOIS). Without a rigorous analysis of the relevant factors leading to or hindering an IOIS adoption it is hard to transfer industry specific results to other contexts. In consequence, Reimers et al. [6] call for a comprehensive consideration of relevant characteristics to understand and manage the adoption of an IOIS.

In their position paper, Lyytinen and Damsgaard [10] propose a configuration perspective on IOIS that reflects the complexity by taking different influential factors into account that foster or hinder the adoption and use of IOIS. Based on their vast conceptual and empirical work in different industries and different countries they conclude that types of IOIS align with a given set of influential factors. A configuration analysis has the potential to carry out rigorous process analyses within each adopter configuration and across 
adopter configurations [10] and thereby close the current gap in IOIS research.

The German furniture industry fulfills the prerequisites for configuration analysis according to Lyytinen and Damsgaard [10] as it includes complex IOIS ("design and use demands coordinated action and they are subject to multiple social constructions and network effects") and provides adopter configurations ("a set of interrelated IOIS adopters united by an organizing vision and associated key functionality, which determine the structure, mode of interaction and appropriation available for the participating organizations"). It consists of several industry segments that differ with respect to product segment, interorganizational forms of cooperation or market influence. Market participants have almost no guidance in what IOIS to adopt in order to support their interorganizational business processes whereas researchers have no insight into the IOIS structure as, to our knowledge, the German furniture industry has never been subject to an in-depth analysis of its interorganizational structures.

To keep our research manageable, we focused on the two largest industry segments (kitchen and upholstery industry segment) that have a combined market share of more than $60 \%$ in the German furniture industry. In both industry segments, manufacturers produce highly configurable products, yet there are differences, for example, in the association structure of the retailers, the technical infrastructure for interorganizational data exchange between enterprise systems or the standardization efforts for IOIS use. Accordingly, the following research questions were formulated: (a) What configurations of interorganizational integration exist in both furniture industry segments kitchen and upholstery? and (b) What influencing factors lead to the emergence of configurations of interorganizational integration in both furniture industry segments kitchen and upholstery? This study aims to (1) provide guidance for market participants in their effort to adopt and use IOIS, (2) to reveal and analyze interorganizational structures in the German furniture industry for the first time and (3) apply and reflect on the proposed configuration analysis on an industry level to assess its applicability as a research method.

In the remainder of this paper, Chapter 2 reviews the state of research on forms of interorganizational integration, the specific notion of configurations of interorganizational integration and the influencing factors that affect them. Subsequently, the multi-stage research approach is explained (Chapter 3). Chapter 4 highlights the results. Chapter 5 provides a discussion and critical appraisal while Chapter 6 closes with our conclusions and a brief outlook.

\section{Forms of interorganizational integration}

Numerous forms of interorganizational integration can be found in literature, focusing on different aspects. Many definitions refer to one or more levels in which a classification of forms of interorganizational integration perceived by the respective researchers is formulated. Examples are the works of Choudhury [11], Benasou and Venkatraman [12], and Schubert [13].

However, the mere definition of forms of interorganizational integration marks only the beginning of a systematic examination of interorganizational structures and the IOIS that support them. As typical descriptive models, classification models in interorganizational integration provide a comprehensive collection of all possible IOIS manifestations. Well-known approaches have been developed by Barrett and Konsynski [14] or Hong [15], among others. They mainly focus on the classification of an IOIS considering different criteria, usually related to technological, organizational and/ or institutional characteristics. However, these modeling approaches usually lack any developmental perspective since the characteristics of an IOIS do not necessarily indicate the influencing factors and change mechanisms leading to their emergence.

\subsection{Adopter Configurations of interorganizational integration}

Lyytinen and Damsgaard [10] understand IOIS adopter configurations as organized clusters of IOIS users that are subject to selected influencing factors, so-called key elements. In doing so, they criticize diffusion theory derived adoption studies as such works typically explain one or only few adopter's behaviors. Adopter configurations refer to similar uses of the concept of configuration in physics, organizational research, or service science, which in their view are transferable to the IOIS domain. A wellknown definition stems from Miller and Friesen [16], who relate configurations to the organizational context: "These can be defined as commonly occurring clusters of attributes or relationships [...] that are internally cohesive, such that the presence of some attributes suggests the reliable occurrence of others." Accordingly, a configuration is based not only on the individual factors (attributes or relationships), but also on the dependencies existing between them (internally cohesive). Meyer et al [17] emphasize "coherent patterns" that result from the interdependencies of the individual attributes. 
Configurations are thus not based on a random set of individual factors but reflect a limited number of stable states [10].

The configuration types proposed by Lyytinen and Damsgaard [10] (dyad, hub and spoke, industry, and community) and the key elements describing them (organizing vision, key functionality, mode of interaction, structure, and mode of appropriation) represent a selection of the configurations and influencing factors they found during their research. This selection is not exhaustive considering existing research, but it is one of the first works to provide a conceptual framework for a holistic examination of interorganizational forms of integration and the influencing factors that affect them.

\subsection{Factors influencing forms of interorganizational integration}

Typical forms of interorganizational integration depend on factors at the institutional, organizational and technical level (exemplary references are [8], [13]). Although some works do not explicitly mention such factors, they can be deduced from the respective context. For example, Modol and Muniategui [18] characterize four IOIS types using the two influencing factors of power and rules. Still, in the "Market" type, for example, the influencing factor "Competition" is included, while in the "Hub" type the factors intercompany relationships and contractual arrangements have an additional impact.

Implicit investigations or analyses of influencing factors can be found in many contributions. However, there is rarely a common conceptual view of forms of interorganizational integration and their respective influencing factors. Mostly, there are studies motivated by single perspectives (see Information Sharing [14], IOIS Implementation [18], or Transaction Costs [19]), which selectively pick out single influencing factors and examine them in the context of their perspective. In their position paper, Lyytinen and Damsgaard [10] propose the configuration perspective as an adequate analytical lens to gain a more comprehensive analytical view on forms of interorganizational integration and their influencing factors.

\section{Research Approach}

Lyytinen and Damsgaard's [10] configurational analysis does not provide predefined procedures for a research project, but only a limited number of suggestions based on a chosen research interest. The exploratory nature of the research suggests that the research methods used must be flexible enough to allow the researcher sufficient freedom to be creative in gathering information [20]. According to the problem statement (see Chapter 1), there is a lack of methodological and content-related information to be able to meaningfully answer the research questions posed about the furniture industry. Consequently, a data collection in the relevant scientific literature for the delimitation of the configuration term as well as the operationalization of the configuration analysis is as necessary as the empirically based determination of configurations in the two industry segments. Accordingly, a multi-phase research procedure based on configuration analysis [10] was developed, comprising four main phases.

Phase 1: Literature search and analysis according to Hart [21] and Saldaná [22] ((1) Identification and acquisition of relevant literature contributions on configurations of interorganizational integration: we conducted a literature search in relevant journal publications according to the JOURQUAL journal ranking used in Germany, corresponding conference proceedings and books. We did four rounds of literature search combining IOIS-related terms (for example "interorganizational system") with seven configuration-related terms from literature (configuration, taxonomy, typology, category, classification, cluster, type). We found 14.678 publications from which only 38 contained material related to IOIS configuration analysis; (2) Analysis of the found literature contributions regarding configuration types and influencing factors: we applied descriptive coding to identify 76 configuration instances and 31 influencing factors described in the publications; (3) Derivation of a frame of reference for further use in the data collection phase: aggregation of the configuration instances lead to three configuration types (dyadic, star-shaped and intermediary) and six categories of influencing factors (product features, competition, power, relationships, structure and function) included in the frame of reference used in the second data collection phase).

Phase 2: Data collection ((1) Development of a semi-structured interview guideline: based on the frame of reference with its configuration types and categories of influencing factors we developed 24 questions regarding institutional, organizational and technical aspects; (2) Selection of relevant actors using "snowball or chain sampling" [20]: we chose this strategy as the existing structures in the industry segments only became apparent from interview to interview and new interview partners could thus be identified. In total, 21 interview partners from 19 companies and organizations (8 CEOs, 1 member of a supervisory board, 4 CIO, 3 IOIS experts, 3 marketing 
experts, 2 sales experts), were identified and interviewed using this sampling strategy; (3) Conducting 21 in-depth interviews with 19 companies/organizations and transcription [22]: overall we produced 30 hours of audio material that we transcribed for further analysis)).

Phase 3: Data analysis ((1) Descriptive and Structured coding of interview transcripts [22]: we performed three coding cycles. In each cycle the results of selected interviews (first two interviews in the first coding cycle, 10 interviews in the second coding cycle and the remaining 9 interviews in the third coding cycle) were compared with the theoretical frame of reference and led to an adaptation and extension of the code scheme. After coding we identified 584 codes reflecting IOIS adopter configurations and their influencing factors; (2) Analysis of the 584 identified codes: in addition to identifying configurations and influencing factors we applied the network view function of the software ATLAS.ti to identify code neighbors (that is codes which have coded the selected text passage next to the original code) that indicate a logic correlation) and identified so-called code chains that reflected direct and indirect relations between configurations and corresponding influencing factors).

Phase 4: Validation ((1) Validation of statements using content triangulation ([23]): we interviewed not only different industry participants, but also at least two representatives from each role (if possible), so that both an intra-role and cross-role review of the statements was possible; (2) Validation with supporting documents: Accompanying documents (including market studies, press articles, standardization documents) and observations (including participation in standardization board meetings) supplemented the interview data).

\section{Interorganizational configurations in the kitchen and upholstery industry segments.}

We identified a total of 39 influencing factors (see Figure 1) in seven categories from the coding analysis of the 21 interviews, with 7 factors (market dominance of chain stores, competition from private brands (retailers), competition from private brands (purchasing association), barrier to vertical integration of manufacturers, organizational services by purchasing associations, master data management by purchasing associations and organization of intermediaries) influencing both industry segments. In the kitchen segment, 18 influencing factors can be assigned to the configurations, while in the upholstery industry segment there are 28 factors. The influencing factors and configurations of interorganizational integration found in both industry segments can additionally be identified and discussed at different levels of analysis: Trade Relations level, Technical Realization level and Standardization level. Their identification and description reflect on the relevant actors in them and their importance for the emergence of the observed configurations of interorganizational integration.

\subsection{Level of Trade Relations}

Two types of data can be identified that need to be exchanged: master data for exchanging information about the assortment agreed between trading partners (mainly catalog data), and transaction data for exchanging business documents, such as an order. A retailer negotiates with a manufacturer the assortment to be supplied by the latter and receives the relevant catalog data. Based on the catalogue, the retailer orders a kitchen or upholstery furniture for the end customer. Retailers in both industry segments are organized in purchasing associations, which are primarily intended to realize price advantages over the manufacturers. Over the decades, purchasing associations have evolved into so-called organizational associations that offer their members other services, such as product catalog management. They serve as intermediaries between manufacturers and their affiliated retailers.

At the level of trade relations, the same configuration types are found in both industry segments: The dyad is a representative of bilateral exchange relationships of master and transaction data between manufacturers' and retailers' enterprise systems (D) while the intermediary configuration serves as a representative of hub-and-spoke-like structures (INT), in which a central actor takes over the coordination of data exchange (see Table 1). Both industry segments have similar business models and actor constellations, which manifest in the stable exchange relationships.

Comparing the factors influencing the respective configurations, there were only small differences observable. Competition between industry actors in the kitchen segment is largely stable, while the structural prerequisites for dyadic configurations are mainly in place at large companies. In both industry segments exist so-called association retailers (smaller companies that rely on the negotiation power of the affiliated purchasing association) and chain store retailers (larger companies with several outlets in different cities). In the upholstery segment larger companies massively drive the development of dyadic 
configurations. This circumstance is reflected at the level of trade relations in the influencing factor "Competition UCS ". Electronically supported product planning is not yet permanently established in the upholstery segment, in contrast to the kitchen segment. So, several industry actors (mainly chain store retailers) have a high motivation to establish permanent business relationships with their trading partners using UCS technology.

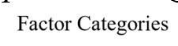

segment). The industry configuration (IND), which is realized by IM1, has hardly any impact, since only few selected catalogs are exchanged. The IM1-based configuration is mainly used for data transfer of specialized assortment data.

(3) IT service provider offer central settlement services for smaller retailers (so-called del credere takeover) to protect against the insolvency of association members. They realize the triad Competition

$$
\text { Sิ }
$$

Business model IM2 Business model IMI Business model KPS Business model UCS Critical madel UCS Critical mass IM2

Barrier Vertical Integration
Private brands (retailer)
Private brands (associations)
Data completeness (chain store)
Competition KPS
Competition UCS

Blockade (technology)
Influence retailer on IM2
Purtner dependency (manufacturer)
Independence from software vendor (retail)

$\mid$\begin{tabular}{|c|}
\hline Price complexity kitchen \\
Price complexity upholstery \\
Product complexity kitchen \\
Product complexity upholstery
\end{tabular}

کิ ationships \begin{tabular}{|c|c|}
$\begin{array}{c}\text { Shortage of skilled workers (chain stores) } \\
\text { Organization IM1 }\end{array}$ & $\begin{array}{c}\text { Strategic Alliance IMI \& Association } \\
\text { Strategic Alliance IM1/nmedia } \\
\text { Strategic alliance software vendor (retail) \& IM2 } \\
\text { Initiative Data integration } \\
\text { Initiative Standardization }\end{array}$ \\
\hline
\end{tabular}

Abbreviations:

IM1 = Intermediary number $1 \quad$ KPS $=$ Kitchen Planning System IM2 = Intermediary number 2 UCS = Upholstery Configuration system

Figure 1: 39 factors influencing IOIS adopter configurations in the German furniture industry

\subsection{Level of Technical Realization}

At the technical realization level, there are three additional actors in the kitchen segment that have an active role in interorganizational data exchange: (1) KPS (kitchen planning software) vendors provide support in the electronic planning of kitchens. In the context of master data exchange, the KPS vendors take on a formative role. They organize the provision of catalog data to retailers' enterprise systems as an intermediary configuration type (INT) ( 31 mentions in 16 interviews). This configuration does not reflect a hub-and-spoke configuration in the sense of Lyytinen and Damsgaard [10]. Here, the data access does not depend on an association membership, but on whether the respective retailer is a customer of the KPS vendor. The configuration is a closed system.

(2) The intermediary IM1 offers services for catalog and transaction data exchange between manufacturers and retailers in both industry segments (transaction data in the kitchen industry and both catalog and transaction data in the upholstery configuration (T), which describes an associationtypical phenomenon.

There are two additional actors in the upholstery segment: (1) Upholstery configuration systems (UCS) vendors have made serious progress in realizing an intermediary configuration type (INT) to make catalog data from the manufacturers available to retailers, with the catalog data being enhanced accordingly with graphics. This is attributed to requirements from the retailers ("information transparency sales", "shortage of skilled workers"). This configuration type has a much lower prevalence, as UCS vendors have not yet established themselves as data intermediaries in the upholstery industry segment in the same way as KPS vendors in the kitchen industry segment

(2) Two intermediaries are active in the upholstery industry segment: IM1 distributes in addition to transaction data (kitchen segment) catalog data from few manufacturers to retailers via its platform. Thus, IM1 has more significance as a neutral data intermediary in the upholstery segment than in the kitchen segment. IM2 implements bidirectional integration solutions between two business partners 
(manufacturer and retailer), which are deeply integrated into the respective production systems (manufacturer) and enterprise resource planning systems (retailer). Such a dyadic configuration enables almost complete data and application integration, through which both catalog and transaction data can be exchanged. The integration is realized via a proprietary data format that is not available to competitors.

\subsection{Level of Standardization}

The standardization board (SB) is an additional actor on the level of standardization in the kitchen industry segment. SB acts as a standardization body for the two industry segments kitchen and upholstery. Its task is to define and approve new versions of the data standards assigned to it. Especially manufacturers hope to achieve efficiency benefits in the processing of retails orders using data standards.

The initiative to establish SB came from the manufacturers, who understand themselves as data suppliers for the retailers. This self-image has led to SB not only being involved in data standardization, but also providing services as an intermediary. Almost all manufacturers who sell kitchens in Germany via the retail network currently upload their catalog data to this server and make it available to retailers and KPS vendors free of charge. Business transactions are not processed via the central SB offering.

In the first industry configuration (IND), the KPS vendors regularly supply themselves with the current manufacturer product catalogs provided in the industry-wide "IDM kitchen" data format, which they import in their kitchen planning systems. This configuration corresponds to an industry configuration according to Lyytinen and Damsgaard [10], as it provides open access to the manufacturers' catalogs for all registered industry actors.

The second industry configuration supported by SB (IND) has retailers, rather than KPS vendors, in the role of data consumer. However, this configuration has currently only little impact, as the processing and provisioning of data is mainly done by the KPS vendors. So far (as of June 2021), there are only three listed retailers that are registered with the master data

Table 2. Nested configurations (organizational association retailers, master data)

server and obtain catalog data.

There is currently no configuration of interorganizational integration at the standardization level in the upholstery industry segment. SB offers the services of the master data server only for the IDM Kitchen standard. The dissemination of catalog data in

Table 1. Configurations overview of interorganizational integration in the German furniture industry

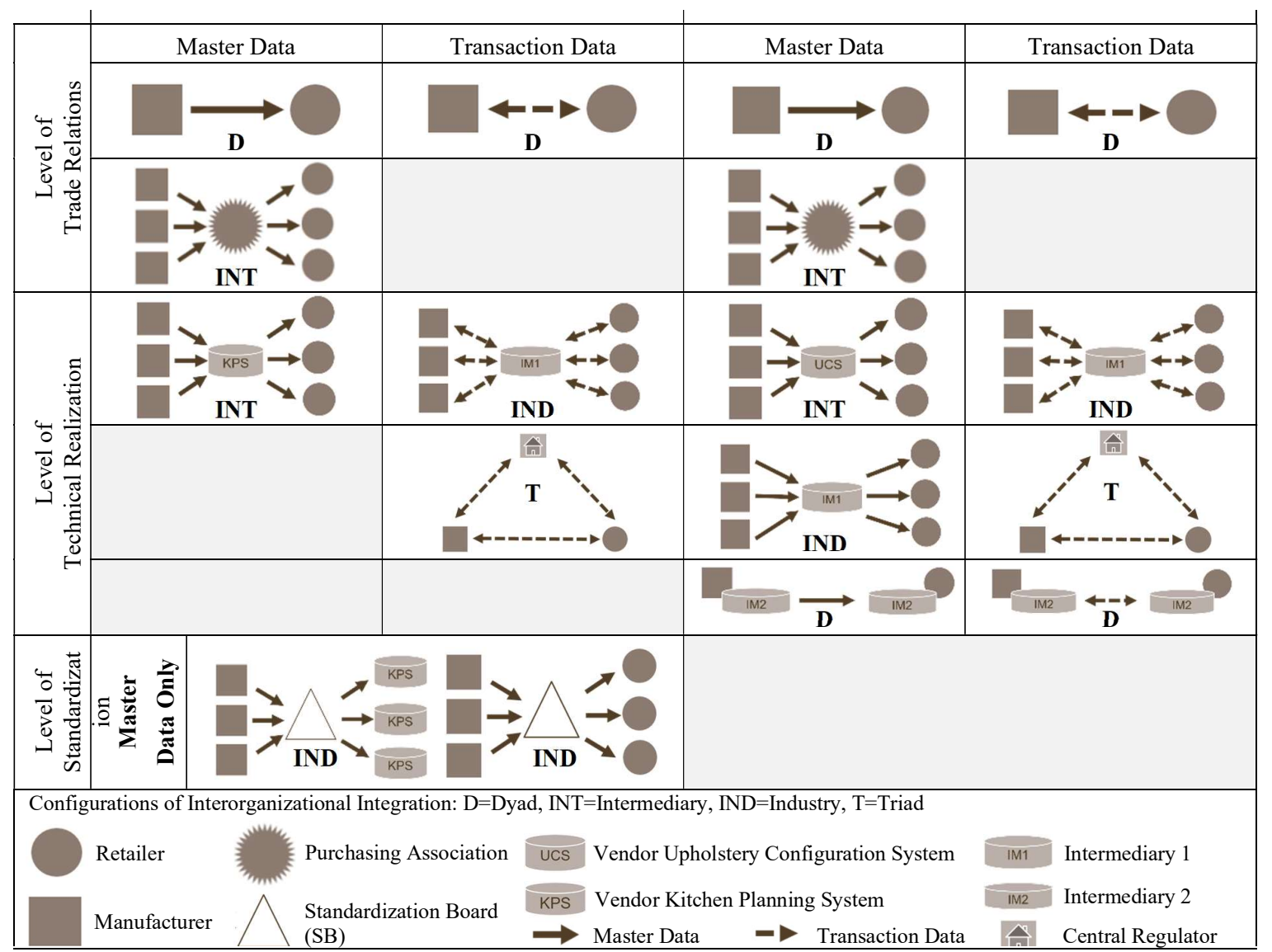


"IDM Upholstery" format is currently left to respective industry actors themselves.

\subsection{Nested IOIS Configurations in the kitchen and upholstery industry segments}

Reflecting on the results of this work in light of the position paper by Lyytinen \& Damsgaard [10], the notion of nested configurations will be discussed. They define nested configurations as an appearance of configurations that are used at the same time and can overlap. That is, an organization uses more than one configuration at a time to exchange data with its connected partners. Thus, they concur with de Corbiere \& Rowe [19], who characterize the existence of nested configurations in everyday operations as a common phenomenon.

Indeed, the configuration analysis shows that exclusive use of only one configuration does not occur in either industry segment. In the following, the retail perspective is used to discuss the nested configurations, since retailers have many different options for data exchange as data recipients (master and transaction data) and data senders (transaction data). The retail perspective is further differentiated into an association retailer perspective and a chain store retailer perspective.

\subsubsection{Association retailers (kitchen \& upholstery) - master data}

Association retailers are trapped in their respective association organization (see Table 2). They are dependent on the organizational associations to provide the master data. Although there are exclusive assortments, especially in the upholstery segment, there is still a small number of exclusive product catalogues compared to the number of product catalogue in an association assortment.

In the upholstery segment, there is also a lack of established structures by UCS vendors compared to the KPS vendors, so that the association services are the main source for master data procurement. A direct connection via IM2 is not possible for the association retailers due to the restrictive association organization. In the kitchen segment, data is mainly provided by the KPS vendors. Here, it is irrelevant for a kitchen retailer whether the data is downloaded directly from SB or is provided by their KPS vendor.

\subsubsection{Association retailers (kitchen \& upholstery) - transaction data}

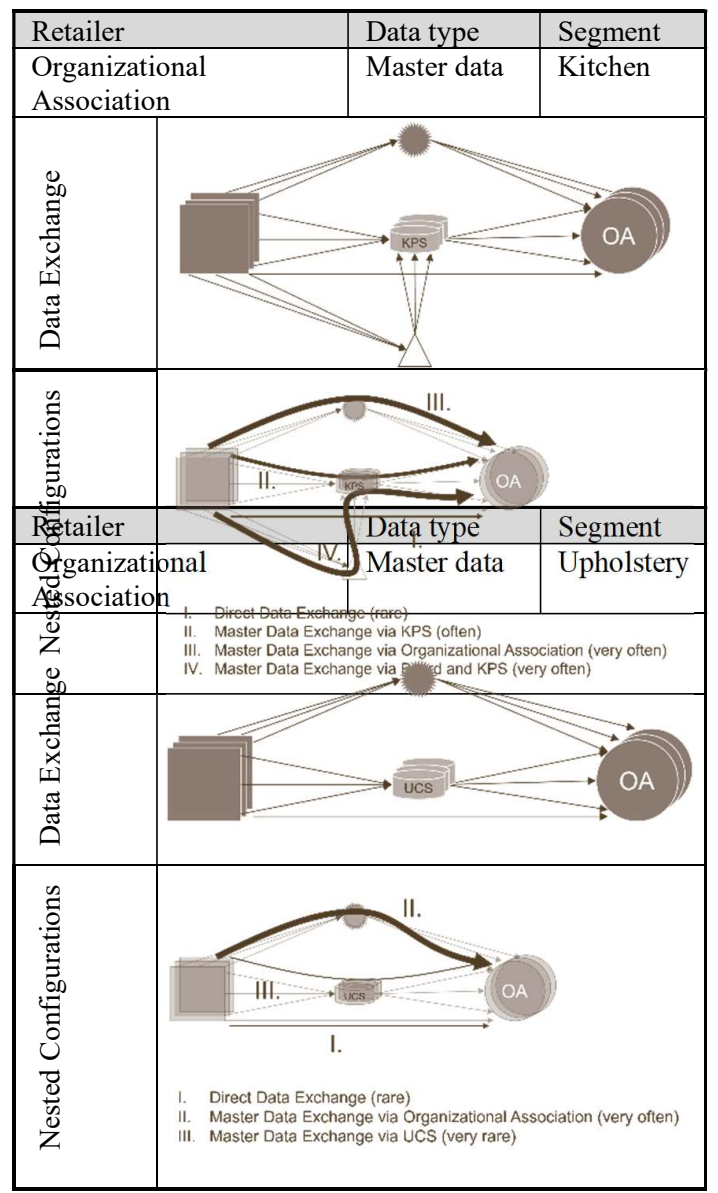

The exchange of transaction data between association retailers and manufacturers is organized in almost the same way (see Table 3). Direct data exchange is used most frequently whereas the total share of electronic data exchange is exceptionally low for smaller retailers. The intermediary services of IM1 are used only very rarely, because IM1 has too few manufacturers connected to their platform to be a serious alternative to the dyadic configuration. The INT configuration is used for ordering specialized assortment (kitchen equipment). 
Another difference between the two segments is the number of orders that is placed with the manufacturers. In the case of the kitchen segment, the planning data from the kitchen planning systems is transferred to the manufacturer as a supplement of the order itself. In the upholstery segment, there are currently only a few planning tools that transfer additional planning data. However, this difference hardly significant for the processing of the transaction data.

Table 3. Nested configurations (organizational association retailers, transaction data)

\begin{tabular}{|c|c|c|c|}
\hline \multicolumn{2}{|c|}{ Retailer } & Data type & Segment \\
\hline \multicolumn{2}{|c|}{$\begin{array}{l}\text { Organizational } \\
\text { Association }\end{array}$} & $\begin{array}{l}\text { Transaction } \\
\text { data }\end{array}$ & $\begin{array}{l}\text { Kitchen \& } \\
\text { Upholstery }\end{array}$ \\
\hline \multicolumn{4}{|c|}{ 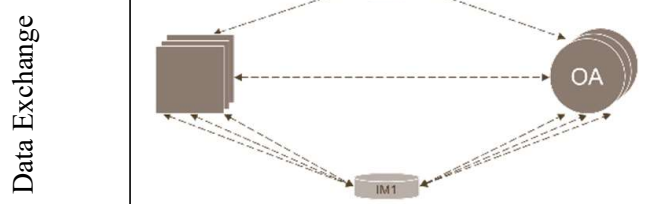 } \\
\hline 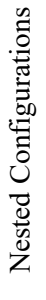 & $\begin{array}{l}\text { I. } \\
\text { ii. } \\
\text { iil. }\end{array}$ & $\begin{array}{l}\text { hange via IM1 (very ro } \\
\text { ta Exchange (very ofte } \\
\text { hange via Central Reg }\end{array}$ & tion (very often) \\
\hline
\end{tabular}

\subsubsection{Chain store retailers (kitchen \& upholstery) - master data}

Chain store retailers seek total control over their catalog data. Most of them have their own departments for processing and maintaining the data. Direct data exchange, for example, is used much more frequently than in the case of association retailers, as there are more bilateral agreements with manufacturers that bypass association negotiations (see Table 4).

Additionally, the chain store retailers in the kitchen segment have the option of obtaining master data via the SB configuration. However, this is of no interest to most chain store retailers because of the established KPS configurations. Compared to the kitchen segment, large retailers in the upholstery segment have adopted the dyadic IM2 configuration. The UCS configurations are currently in the process of being set up, so that data provision via these configurations is rarely used. Intermediary IM1 is not an alternative for master data exchange in the upholstery segment due to too few data suppliers.
Table 4. Nested configurations (chain store retailers, master data)

\begin{tabular}{|l|l|l|l|}
\hline Retailer & Data type & Segment \\
\hline Chain & Master data & Kitchen \\
Store & & \\
\hline
\end{tabular}

\subsubsection{Chain store retailers (kitchen \& upholstery) - transaction data}

As a chain store retailer in the kitchen segment, transactions are usually processed directly with the manufacturer's enterprise system, as is the case with any association retailer (see Table 5). As a chain store retailer in the upholstery segment, transactions are also generally processed directly with the manufacturer, with the IM2 interface often being used for business document exchange like orders or invoices. A retailer and a manufacturer can exchange both catalog and transaction data between their two integrated enterprise systems with the IM2 configuration. The IM1 configuration is rarely used in both segments due 
to the insufficient critical mass of exchange partners for an intermediary. The processes to exchange transaction data and the applied configurations hardly differ from one another. The exchange of transaction data follows well-established procedures and uses well-known interorganizational systems.

Table 5. Nested configurations (chain store retailers, master data)

\begin{tabular}{|l|l|l|l|}
\hline Retailer & Data type & Segment \\
\hline Chain & Master data & Kitchen \\
Store & & & \\
\hline & & & \\
\hline
\end{tabular}

\section{Discussion and Limitations}

Our study had mainly three goals in answering our research questions (see Chapter 1): (1) provide guidance for market participants, (2) to reveal interorganizational structures in the German furniture industry for the first time and (3) apply and reflect on the proposed configuration analysis on an industry level to assess its applicability as a research method.
(1) The configuration analysis and its corresponding influencing factors provide the basis for detailed industry actor profiles to assess IOIS configuration options similar to related works from [12], [3]. It even provides the means to assess parallel use of (nested) configurations [19]. In contrast to many similar attempts to identify and analyze relevant IOIS participants our study highlights the importance of individual actor roles within and between configurations. In previous configuration research IT service providers are hardly given any importance as industry-relevant actors (see [24] for an exception). The configurations provided by IT vendors are usually assigned to respective business partners. However, in this study we found that IT service providers in both furniture industry segments are responsible for seven of 12 identified configurations.

(2) Our study identifies and analyzes IOIS adopter configurations in the German furniture industry for the first time. Our results must be assessed according to several limitations: we interviewed 19 organizations in two industry segments of the furniture industry. Although both have a market share of more than $60 \%$ the results do neither reflect all existing configurations in the industry nor all existing market participants. The configurations originate from different motives of the actors, which have partly economic, partly normative backgrounds. The factors influencing the emergence of configurations can therefore be regarded as industry specific. A generalization of the configurations to other industries (segments) is possible insofar as the configurations themselves can be found as a model representation in many different areas (see [12], [19] for similar approaches). Configurations can thus be used as formative elements of a model of interorganizational cooperation.

(3) To apply configuration analysis to our research object we had to operationalize the conceptual idea (see Chapter 3) based on [10]. The explorative research design with in-depth interviews and the use of descriptive and structured coding of the transcribed interviews may serve other researchers to conduct similar studies. Still, the very nature of our research object (IOIS adopter configuration) suggests a complex and multi-level phenomenon that has to be subject to other research methods complementing the original explorative research design (see [12] (cluster analysis) or [2] (comparative case studies) for alternative approaches).

\section{Conclusions and Outlook}

The presented work was one of the first to operationalize the configuration analysis conceptually proposed by Lyytinen and Damsgaard [10]. Four 
configuration types (industry, dyad, intermediary, and triad) and seven categories of 39 influencing factors (competition, power, product attributes, relationships, structure, functions, customer requirements) were identified. According to the previous discussion we find several aspects to be interesting to improve future configuration analysis approaches:

Actor roles: It is necessary to clarify the influence of IT vendors in future studies. Levels of analysis: The main levels of analysis identified (trade relations, technical realization and standardization) and data types (master and transaction data) may be subject to change in future configurations. For example, strategic information (like real-time customer demand data) rather than master data may be relevant for data exchange [25]. Thus, the focus of the analysis perspectives must be chosen depending on the object and goal of the investigation.

\section{References}

[1] C. Steinfield, "Inter-organizational Information Systems," in Computing Handbook, Third Edition, Volume 2: Information Systems and Information Technology, H. Topi and A. Tucker, Eds. CRC Press, 2014, pp. 1-33.

[2] A. Nagy, "Collaboration and conflict in the electronic integration of supply networks," 2006.

[3] K. Reimers and R. B. Johnston, "The difficulty of studying inter-organisational IS phenomena on large scales: critical reflections on a research journey," Electron. Mark., vol. 20, pp. 229-240, 2010.

[4] F. de Corbière, F. Rowe, and C. S. Saunders, "Digitalizing interorganizational relationships: Sequential and intertwined decisions for data synchronization," Int. J. Inf. Manage., vol. 48, pp. 203-217, Oct. 2019.

[5] D. Chatterjee and T. Ravichandran, "Interorganizational Information Systems Research: A Critical Review and an Integrative Framework," in 37th Hawaii Internatioal Conference on System Sciences, 2004, pp. 1-10.

[6] K. Reimers, R. B. Johnston, and S. Klein, "A Theorizing Evolution of Inter-Organizational Information Systems on Long Timescales," 2008.

[7] J. Kauremaa and K. Tanskanen, "Designing interorganizational information systems for supply chain integration: A framework," Int. J. Logist. Manag., vol. 27, no. 1, 2016.

[8] S. Gregor and R. B. Johnston, "Developing an Understanding of Interorganizational Systems: Arguments for Multi Level Analysis and Structuration Theory," in Proceedings of the European Conference on Information Systems, 2000, pp. 1-9.

[9] G. Premkumar and K. Ramamurthy, "The Role of Interorganizational and Organizational Factors on the Decision Mode for Adoption of
Interorganizational Systems*," Decis. Sci., vol. 26, no. 3, pp. 303-336, 1995.

[10] K. Lyytinen and J. Damsgaard, "Interorganizational information systems adoption--a configuration analysis approach," Eur. J. Inf. Syst., vol. 20, pp. 496-509, 2011.

[11] V. Choudhury, "Strategic Choices in the Development of Interorganizational Information Systems," Inf. Syst. Res., vol. 8, no. 1, pp. 1-24, 1997.

[12] M. Bensaou and N. Venkatraman, "Configurations of Interorganizational Relationships: A Comparison Between U.S. and Japanese Automakers," Management Science, vol. 41, no. 9. pp. 1471-1492, 1995.

[13] P. Schubert, "Integration Scenarios for Business Collaboration," in AMCIS 2008 Proceedings, 2008, p. Paper 258.

[14] S. Barrett and B. Konsynski, "Inter-Organization Information Sharing Systems," MIS Q., vol. 6, no. 4, pp. 93-105, 1982.

[15] I. B. Hong, "A new framework for interorganizational systems based on the linkage of participants' roles," Inf. $\{\&\}$ Manag., vol. 39, no. 4, pp. 261-270, 2002.

[16] D. Miller and P. H. Friesen, Organizations: A Quantum View. Englewood Cliffs, NJ: PrenticeHall, 1984.

[17] A. D. Meyer, A. S. Tsui, and C. R. Hinings, "Configurational approaches to organizational analysis," Acad. Manag. J., pp. 1175-1195, 1993.

[18] J. R. Modol and F. S. Muniategui, "Structural Configurations: An Explanation for IOIS Implementation Failure," in 16th European Conference on Information Systems, 2008, pp. 974-984.

[19] F. de Corbiere and F. Rowe, "Understanding the Diversity of Interconnections between IS: Towards a New Typology of IOS," in Proceedings of 19th European Conference on Information Systems (ECIS 2010), 2010, pp. 1-13.

[20] N. Blaikie, Designing Social Research. Cambridge: Polity Press, 2000.

[21] C. Hart, Doing a Literature Search A Comprehensive Guide for the Social Sciences. London: Sage Publications, 2001.

[22] J. Saldaña, The coding manual for qualitative researchers. London, Thousand Oaks, New Delhi: Sage Publications, 2009.

[23] M. Q. Patton, Qualitative Research \& Evaluation Methods: Integrating Theory and Practice, 4th Editio. Thousand Oaks: Sage Publications, 2015.

[24] K. Kumar and H. G. van Dissel, "Sustainable Collaboration: Managing Conflict and Cooperation in Interorganizational Systems," MIS Q., vol. 20, no. 3, pp. 279-300, 1996.

[25] S. Li and B. Lin, "Accessing information sharing and information quality in supply chain management," Decis. Support Syst., vol. 42, no. 3, pp. 1641-1656, 2006. 